the Canadian Infectious Diseases Society and the Canadian Thoracic Society. Clin Infect Dis 2000;31:383-421. http://dx.doi.org/10.1086/313959

14. Menéndez R, Torres A, Aspa J, Capelastegui A, Prat C, Rodríguez de Castro F. Community-Acquired Pneumonia. New Guidelines of the Spanish Society of Pulmonology and Thoracic Surgery (SEPAR). Arch Bronconeumol
2010;46(10):543-58. http://dx.doi.org/10.1016/j.arbres.2010.06.014

15. Woodhead M, Blasi F, Ewig S, et al. Joint Taskforce of the European Respiratory Society and European Society for Clinical Microbiology and Infectious Diseases. Guidelines for the management of adult lower respiratory tract infections. Clinical Microbiology and Infection 2011;17:(Suppl 6)

\title{
Correct inhalation technique is critical in achieving good asthma control
}

\author{
*Federico Lavorini', Omar S Usmani² \\ 1 Careggi University Hospital, Department of Experimental and \\ Clinical Medicine, Florence, Italy \\ 2 National Heart and Lung Institute, Imperial College London \& \\ Royal Brompton Hospital, London, UK \\ *Correspondence: Dr Federico Lavorini, Careggi University \\ Hospital, Department of Experimental and Clinical Medicine, \\ Largo Brambilla 3, 50134, Florence, Italy \\ Tel: +39-055-7947516 Fax: +39-055-422320 \\ E-mail: federico.lavorini@unifi.it
}

See linked article by Levy et al. on pg 406

The prevalence of asthma has been reported to range from 1 to $18 \%$ of the population in different countries. ${ }^{1}$ This means that several hundred million patients with asthma rely on the efficacy of their inhalers to achieve asthma control. Undeniably, inhaled therapy remains the cornerstone of treatment for patients with asthma, and the main inhalation devices used are pressurised metered dose inhalers (pMDIs) and dry powder inhalers (DPIs). ${ }^{2}$ Yet there are more than 200 different drug-inhaler combinations available in any medical formulary, and this causes immense confusion amongst prescribers, healthcare professionals and patients.

Published evidence shows that, when used correctly, there is little difference in clinical efficacy between different inhaler types. ${ }^{3}$ However, several studies have reported that a high proportion of patients cannot use their inhalers (either pMDIs or DPIs) well enough to benefit from the treatment. ${ }^{4,5}$ These numbers are even more depressing considering that between 40 to $85 \%$ of healthcare professionals, who should readily be able to teach patients how to use their inhalers correctly, do not seem to be able to perform that task properly - and doctors are the worst amongst all healthcare professionals. $^{6-8}$

It has clearly been shown that failure to use inhalers correctly may result in poor asthma control, ${ }^{8}$ increased cost, ${ }^{9}$ and a greater risk to the patient from exposure to less well-tolerated alternative treatments. In a large cross-sectional study involving over 1600 asthma outpatients, the finding of just one critical error in inhalation technique, irrespective of the inhalation device (DPI or pMDI), was associated with increased emergency room visits, hospitalisation and oral medication prescription. ${ }^{10}$

In this issue of the $P C R J$, Levy and co-workers ${ }^{11}$ retrospectively evaluated pMDIs usage in a large cohort (nearly 4000) of UK primary care patients with asthma, and correlated patients' inhaler technique with the level of asthma control. Patients at British Thoracic Society (BTS) treatment steps 1, 2 and 3 had their asthma status reviewed through the Improving the Management of Patients Asthma and COPD Treatment (IMPACT) service, where specialist nurse advisors undertake asthma reviews in primary care according to protocols based on the UK BTS/SIGN National Asthma Guidelines. ${ }^{12}$ Interestingly, part of the review involved evaluating $\mathrm{pMDI}$ inhaler technique objectively by using the Vitalograph Aerosol Inhalation Monitor, ${ }^{13}$ a training device aimed at assessing three crucial steps needed for correct pMDI usage: slow inhalation flow (below $50 \mathrm{~L} / \mathrm{min}$ ); synchronisation between inhaler actuation and inhalation; and a 5 second breath-hold pause following inhalation.

The authors observed that patients who displayed significant errors when using pMDIs had higher risks of poor asthma control and more bursts of systemic corticosteroid prescriptions than those who operated pMDIs correctly. ${ }^{11}$ Of note, patients who were using pMDIs in conjunction with spacers, or were using breath-actuated inhalers, had better asthma control than those using pMDIs alone. Synchronisation - i.e. achieving the correct inhalation flow following actuation - was the main step in the inhalation technique which most patients failed.

These findings should be interpreted in the context of the retrospective observational nature of the study. We do not know whether other reasons for poor disease control (e.g. co-morbidities, different treatment plans, different drug dosages) were more frequent in patients who misused their pMDI than those who used it correctly. In addition, the UK is rather atypical with respect to device prescription compared to the rest of Europe, where DPIs are the favoured inhalation device. In this current study, only $9 \%$ and $14 \%$ of patients, respectively, used their DPI as reliever, or maintenance, therapy. The investigators did not attempt to assess inhalation technique in the patients prescribed a DPI, nor did they relate DPI technique to asthma control. Certainly there is evidence to show that patients using DPIs may experience more critical errors than those using pMDls. ${ }^{10}$ Despite these limitations, the results of the study by Levy et al. are important: they confirm the relationship between inhaler misuse and poor asthma control, and reinforce the notion of the importance of patients training for efficient inhalation drug delivery. ${ }^{11}$

Patients' ability to handle inhalers correctly is a crucial issue for the choice of the most appropriate inhaler device for a given patient. Adherence to therapy is likely to be influenced by patients' attitudes and their experience in using the device, and if the patient feels that 
their treatment is not working, adherence is likely to be poor with consequently reduced efficacy of treatment. Sometimes incorrect use of inhalers is not simply due to patients' lack of competence, but also to deliberate non-adherence by patients ('contrivance') who use their inhalers incorrectly. ${ }^{9}$

Despite the development of several new and improved types of inhaler device, there has been no sustained improvement over the past 35 years in patients' ability to use their inhalers. ${ }^{4}$ The mantra for how to get patients to use inhalers correctly has been, and still seems to be: "training and more training". ${ }^{2}$ Evidence shows that patients" competence in self-administration of inhaled medications is improved by educational interventions, ${ }^{14}$ and repeated training in correct inhaler use improves asthma symptoms, ${ }^{15}$ quality of life, ${ }^{16}$ lung function, ${ }^{17}$ and reduces the use of reliever medications as well as emergency hospital admissions. $^{18}$

We advocate that choosing an inhalation device for drug administration in patients with obstructive airway diseases is as critical as the choice of medication itself, and that in future, the choice of a new compound will be secondary to the need to choose the appropriate inhaler device for the patient. ${ }^{19}$

Conflicts of interest The authors declare that they have no conflicts of interest in relation to this article. FL is a member of the ADMIT Group, which received an unrestricted educational grant from Meda Pharmaceuticals and is now supported by Chiesi Pharmaceuticals.

Funding Dr Omar S. Usmani is a recipient of a UK National Institute of Health Research (NIHR) Career Development Fellowship and is supported by the NIHR Respiratory Disease Biomedical Research Unit at the Royal Brompton and Harefield NHS Foundation Trust and Imperial College London.

Commissioned article; not externally peer-reviewed; accepted 10th November 2013; online 23rd November 2013

(c) 2013 Primary Care Respiratory Society UK. All rights reserved

http://dx.doi.org/10.4104/pcri.2013.00097

Prim Care Respir J 2013: 22(4): 385-386

\section{References}

1. Global Initiative for Asthma (GINA). The global strategy for asthma management and prevention. Updated 2012. Available from: http://www.ginasthma.org.

2. Lavorini F. Corrigan CJ, Barnes PJ, et al. Retail sales of inhalation devices in European countries: so much for a global policy. Respir Med 2011;105(7):1099103. http://dx.doi.org/10.1016/j.rmed.2011.03.012

3. Dolovich MB, Ahrens RC, Hess DR, et al. Device selection and outcomes of aerosol therapy: evidence-based guidelines: American College of Chest Physicians/American College of Asthma, Allergy, and Immunology. Chest 2005;127(1):335-71. http://dx.doi.org/10.1378/chest.127.1.335

4. Crompton GK, Barnes PJ, Broeders M, et al. Aerosol Drug Management Improvement Team. The need to improve inhalation technique in Europe: a report from the Aerosol Drug Management Improvement Team. Respir Med 2006;100(9):1479-94. http://dx.doi.org/10.1016/j.rmed.2006.01.008
5. Lavorini F, Magnan A, Dubus JC, et al. Effect of incorrect use of dry powder inhalers on management of patients with asthma and COPD. Respir Med 2008;102(4):593604. http://dx.doi.org/10.1016/..rmed.2007.11.003

6. Press VG, Pincavage AT, Pappalardo AA. The Chicago Breathe Project: a regional approach to improving education on asthma inhalers for resident physicians and minority patients. J Nat/ Med Assoc 2010;102(7):548-55.

7. Hanania NA, Wittman R, Kesten S, Chapman KR. Medical personnel's knowledge of and ability to use inhaling devices. Metered-dose inhalers, spacing chambers, and breath-actuated dry powder inhalers. Chest 1994;105(1):111-16. http://dx.doi.org/10.1378/chest.105.1.111

8. Haughney J, Price D, Barnes NC, Virchow JC, Roche N, Chrystyn H. Choosing inhaler devices for people with asthma: current knowledge and outstanding research needs. Respir Med 2010;104(9):1237-45. http://dx.doi.org/10.1016/j.rmed.2010.04.012

9. Brennan VK, Osman LM, Graham H, Critchlow A, Everard ML. True device compliance: the need to consider both competence and contrivance. Respir Med 2005;99(1):97-102. http://dx.doi.org/10.1016/..rmed.2004.05.015

10. Melani AS, Bonavia M, Cilenti V, et al. Gruppo Educazionale Associazione Italiana Pneumologi Ospedalieri. Inhaler mishandling remains common in real life and is associated with reduced disease control. Respir Med 2011;105(6):930-8. http://dx.doi.org/10.1016/j.rmed.2011.01.005

11. Levy ML Hardwell A, McKnight E, Holmes J. Asthma patients' inability to use a pressurised metered-dose inhaler (pMDI) correctly correlates with poor asthma control as defined by the Global Initiative for Asthma (GINA) strategy: a retrospective analysis. Prim Care Respir J 2013;22(4).406-11.

http://dx.doi.org/10.4104/pcrj.2013.00084

12. British Thoracic Society, Scottish Intercollegiate Guidelines Network. British guideline on the management of asthma. Thorax 2008;63(Suppl 4):iv1-121. Available from: http://www.sign.ac.uk/guidelines/fulltext/101/index.html http://dx.doi.org/10.1136/thx.2008.097741

13. Lavorini F, Levy ML, Corrigan C, Crompton G; ADMIT Working Group. The ADMIT series - issues in inhalation therapy. 6) Training tools for inhalation devices. Prim Care Respir J 2010;19(4):335-41. http://dx.doi.org/10.4104/pcri.2010.00065

14. Fink JB, Rubin BK. Problems with inhaler use: a call for improved clinician and patient education. Respir Care 2005;50(10):1360-75

15. Wilson SR, Scamagas P, German DF, et al. A controlled trial of two forms of selfmanagement education for adults with asthma. Am J Med 1993;94(6):564-76. http://dx.doi.org/10.1016/0002-9343(93)90206-5

16. Hashmi A, Soomro JA, Memon A, Soomro TK. Incorrect inhaler technique compromising quality of life of asthmatic patients. J Medicine 2012;13(1):16-21. http://dx.doi.org/10.3329/jom.v13i1.7980

17. Newman SP, Weisz AW, Talaee N, Clarke SW. Improvement of drug delivery with a breath actuated pressurised aerosol for patients with poor inhaler technique. Thorax 1991;46(10):712-16. http://dx.doi.org/10.1136/thx.46.10.712

18. Prabhakaran L, Lim G, Abisheganaden J, Chee CBE, Choo YM. Impact of an asthma education programme on patients' knowledge, inhaler technique and compliance to treatment. Singapore Med J 2006;47(3):225-31.

19. Laube $\mathrm{BL}$, Janssens $\mathrm{HM}$, de Jongh $\mathrm{FH}$, et al. European Respiratory Society; International Society for Aerosols in Medicine. What the pulmonary specialist should know about the new inhalation therapies. Eur Respir J 2011;37(6):1308-31. http://dx.doi.org/10.1183/09031936.00166410 